\title{
Agrobiodiversidad: Validación E Identificacion De Flora En La Comunidad Piñancay, Parroquia Capsol, Chunchi-Ecuador
}

\author{
Edmundo Danilo Guilcapi Pacheco \\ Carlos Alberto Rivera Cruz \\ Lisseth Paola Ortiz Cruz.
}

Investigadores, Escuela Superior Politécnica de Chimborazo

doi: 10.19044/esj.2017.v13n24p33 URL:http://dx.doi.org/10.19044/esj.2017.v13n24p33

\begin{abstract}
Ecuador is considered as a country with great biodiversity, in spite of its small territory. This is due to multiple factors including geographic location, geological, topographical and climatic factors, precipitation, temperature, and location in the tropical belt of the planet. On the equinoctial line, with territories located both in the northern hemisphere and in the southern hemisphere, all this forces us to maintain a constant responsibility towards our flora and fauna for its conservation and wealth. Piñancay is one of the six (6) communities of the Capsol parish, which belongs to the Chunchi canton. It has a cold, humid, and cloudy climate that allows the development of agricultural activities on a wide range. It however serves as a form of income to the inhabitants of the sector. Thus, based on the validation and identification of the flora inventory of the Piñancay community and in addition to the morphological and taxonomic identification of the plants, a study was carried out on the current agrobiodiversity of the Piñancay community.
\end{abstract}

Keywords: Agrobiodiversity, biodiversity, flora, Piñancay, Chunchi, Ecuador

\section{Resumen}

El Ecuador es considerado como un país con gran biodiversidad, a pesar de su reducido territorio, debido a múltiples factores entre ellos: la ubicación geográfica, características geológicas, topográficas, climáticas, precipitación, temperatura, además por la ubicación en el cinturón tropical del planeta, sobre la línea equinoccial, con territorios ubicados tanto en el hemisferio norte como en el hemisferio sur, todo ésto, obliga a mantener una constante responsabilidad frente a nuestra flora y fauna para su conservación 
y riqueza. Piñancay es una de las 6 comunidades de la parroquia Capsol, la misma que pertenece al cantón Chunchi, posee un clima frío, húmedo y nublado, permitiendo el desarrollo de actividades agropecuarias en forma amplia, siendo una forma de ingresos de los habitantes del sector. Es así que, a partir de la validación e identificación del inventario de flora de la comunidad Piñancay y además de la identificación morfológica y taxonómica de las plantas se elaboró un estudio de agrobiodiversidad actual de la comunidad Piñancay.

Palabras-claves: Agrobiodiversidad, biodiversidad, flora, Piñancay, Chunchi, Ecuador

\section{Introduction}

La pobreza de acuerdo con Spicker (2009), se toma desde 4 puntos de vista: desde lo material; se asocia directamente con falta de recursos para alcanzar un nivel de vida digno, desde lo económico; se mide con el ingreso asociando términos como nivel de vida, desigualdad y posición económica; desde las condiciones sociales, lo cual se centra en la forma de vida de la población de acuerdo a la clase social, el grado de dependencia, la carencia de seguridad básica, la ausencia de titularidades y la exclusión y finalmente desde el juicio moral, en el cual las personas son pobres cuando se juzga que sus condiciones materiales son moralmente inaceptables. De acuerdo con Phelean (2006), la pobreza describe un conjunto de situaciones que están vinculadas con limitaciones de acceso a recursos para poder satisfacer las necesidades básicas (alimentación, educación, salud, vivienda, agua potable) que tienen incidencia en la vida de las personas.

Dentro de este apartado se encuentra la pobreza rural. En este sentido, Alvarado (2006) manifiesta que los pobres rurales dependen, en gran medida, de la agricultura, la pesca, la silvicultura y de los servicios e industrias de pequeña escala relacionados con esas actividades. De acuerdo con IFAD (2001), el sector pobre de la economía del mundo se encuentra en las zonas rurales quienes conforman las tres cuartas partes de los mil doscientos millones de pobres existentes en el mundo. En la mayoría de los países pobres, la agricultura representa del 50 al 80 por ciento del empleo (Alvarado, 2006). Según Thompson (2003) existen 2,6 mil millones de personas en el mundo que gana menos de 2 dólares al día, más de las tres cuartas de éstas personas, ganan su sustento directamente de la producción agropecuaria o a través de una relación muy estrecha con ella.

La agrobiodiversidad muestra una perspectiva sostenible por los muchos beneficios que esta presenta, como el incremento de la productividad, la cosecha, la seguridad alimentaria, el valor económico y los ingresos GTZ, (2000). Según Castro et al. (2005) el mantenimiento de la 
agrobiodiversidad contribuye a diversificar productos y oportunidades de ingreso para los productores, a reducir la dependencia de materiales genéticos foráneos, a conservar la estructura de los ecosistemas haciéndolos más estables y sostenibles, y a aumentar el empoderamiento y la participación de granjeros y personas de la comunidad. Por su lado Gargoloff et al. (2009) manifiesta que el mantenimiento de los sistemas de agricultura familiar, sus conocimientos y saberes puede ser importante para un manejo adecuado de la agrobiodiversidad y el manejo sustentable de los recursos naturales. Así también, Rojas et al. (2016) menciona que los Andes tienen una gran variabilidad física y ambiental, la misma que es contrarrestada por los agricultores mediante la agrobiodiversidad, es así que ésta representa un componente esencial del sistema productivo y de la seguridad alimentaria en los Andes.

Bajo este contexto el presente artículo tiene como objetivo validar e identificar el inventario de flora de la comunidad Piñancay, además de realizar la identificación morfológica y taxonómica de las plantas con la finalidad de elaborar el estudio de agrobiodiversidad actual de la comunidad Piñancay.

\section{Metodología \\ Localización}

La investigación se llevó a cabo en el área arqueológica del monte Puñay, comunidad Piñancay, Parroquia Capsol, Cantón Chunchi, Provincia de Chimborazo.
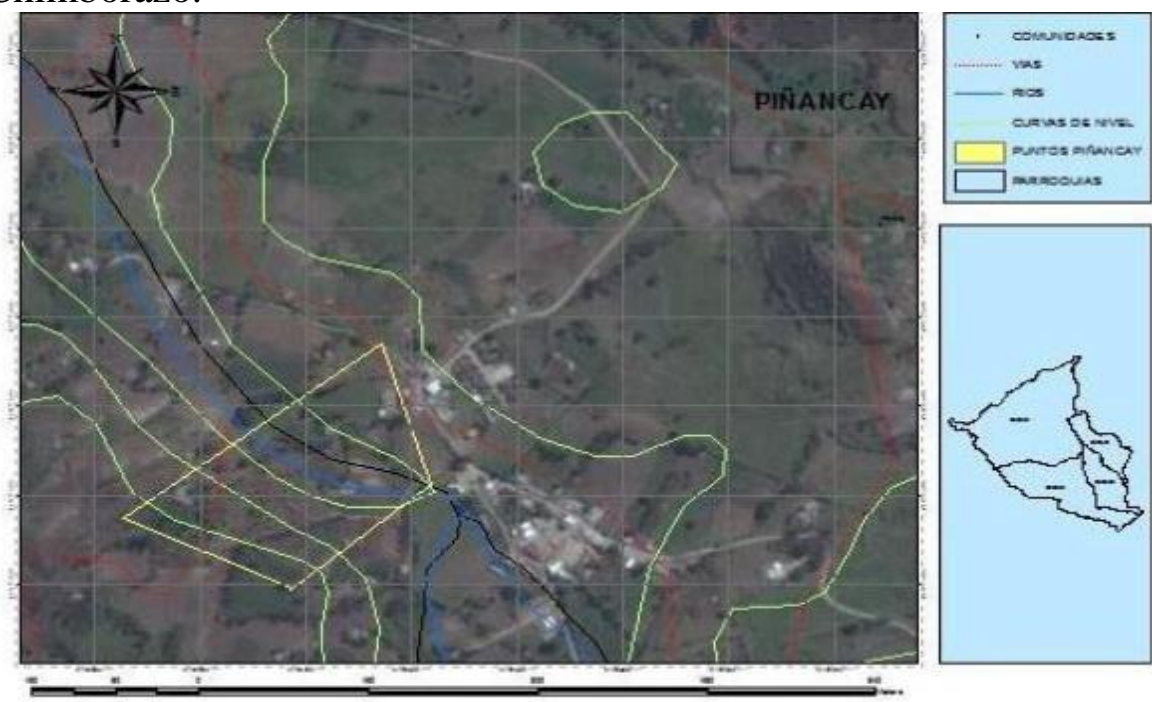

Coordenadas proyectadas UTM Zona $17 \mathrm{~S}$

Datum WGS 84

$\mathrm{X}: 728414 \mathrm{E}$

Y: $9745707 \mathrm{~N}$ 
Validación e identificación del inventario de flora comunidad Piñancay

Mediante revisión documental, se validó el inventario de flora de las plantas domesticadas y silvestres en la comunidad Piñancay. Además se identificaron nuevas especies para lo cual se realizaron salidas de campo con el acompañamiento de dirigentes comunitarios y representantes del Gobierno Parroquial de Capsol.

\section{Identificación morfológica y taxonómica}

A través de revisión documental se realizó el estudio morfológico de las plantas recolectadas, mismas que presentan características como: forma, tamaño, espesor, alto, ancho, entre otros. Así también mediante el mismo método se realizó el estudio taxonómico en donde se logró determinar el orden, género, nombre científico, familias, etc. 


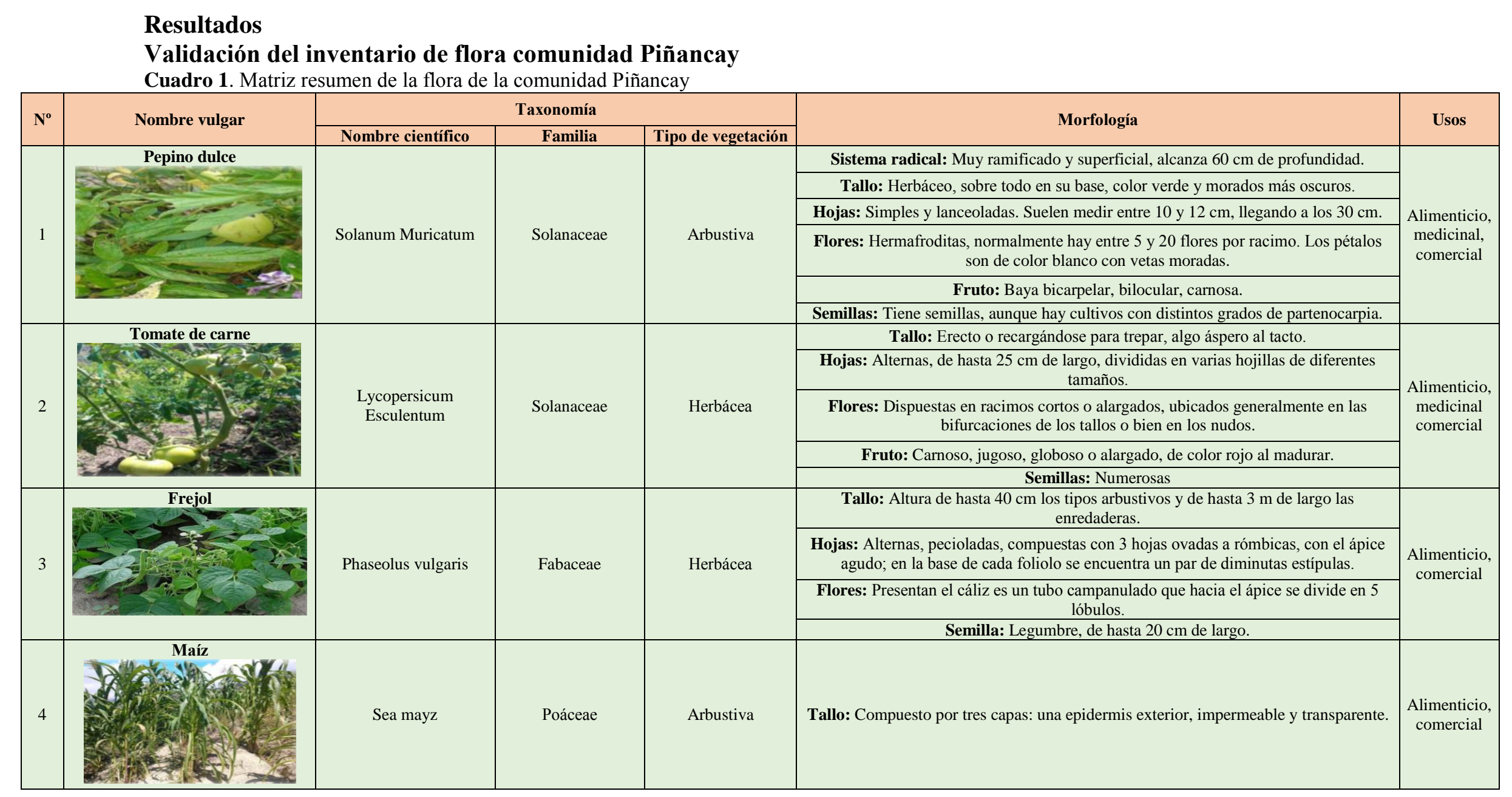




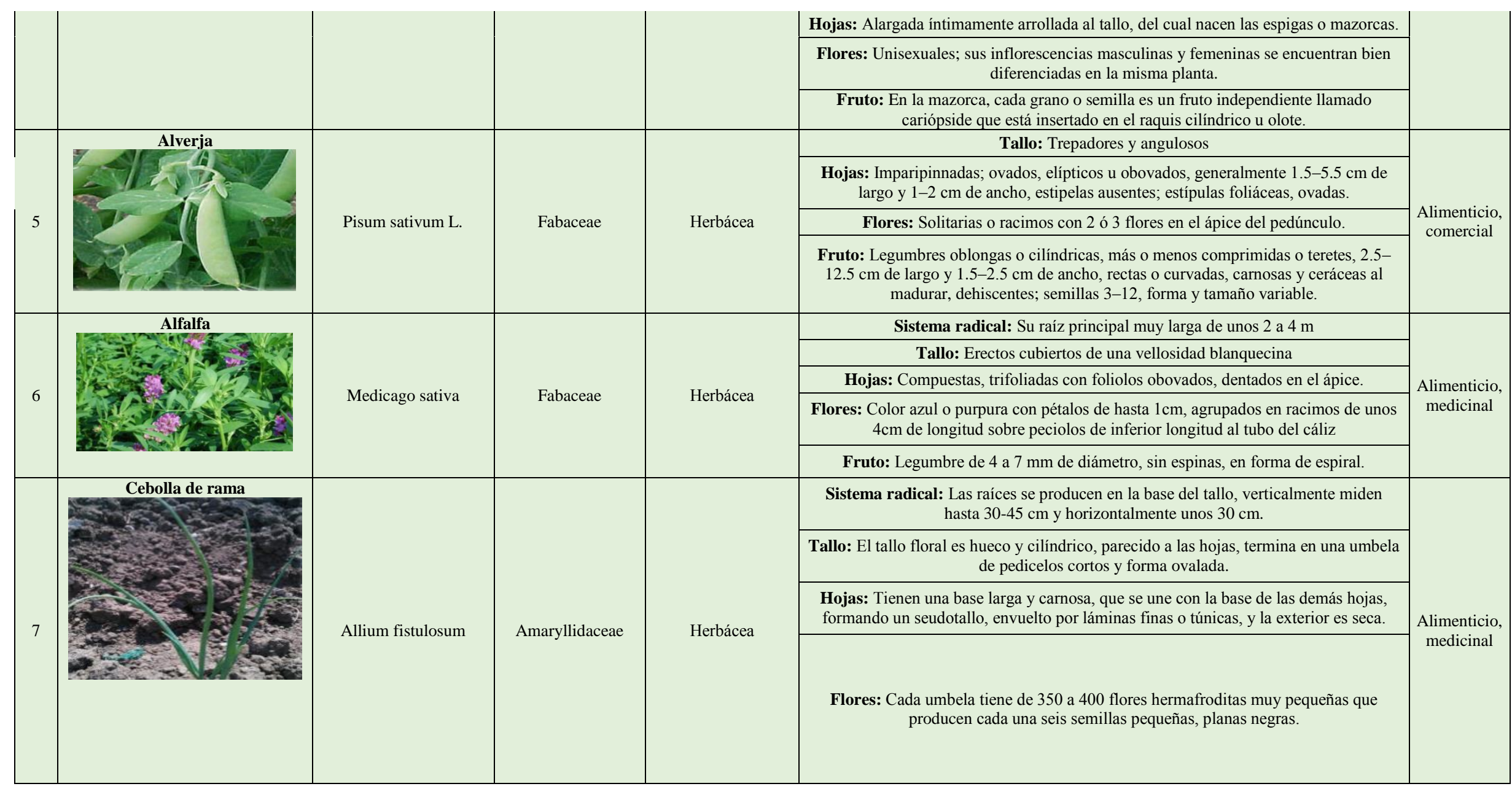




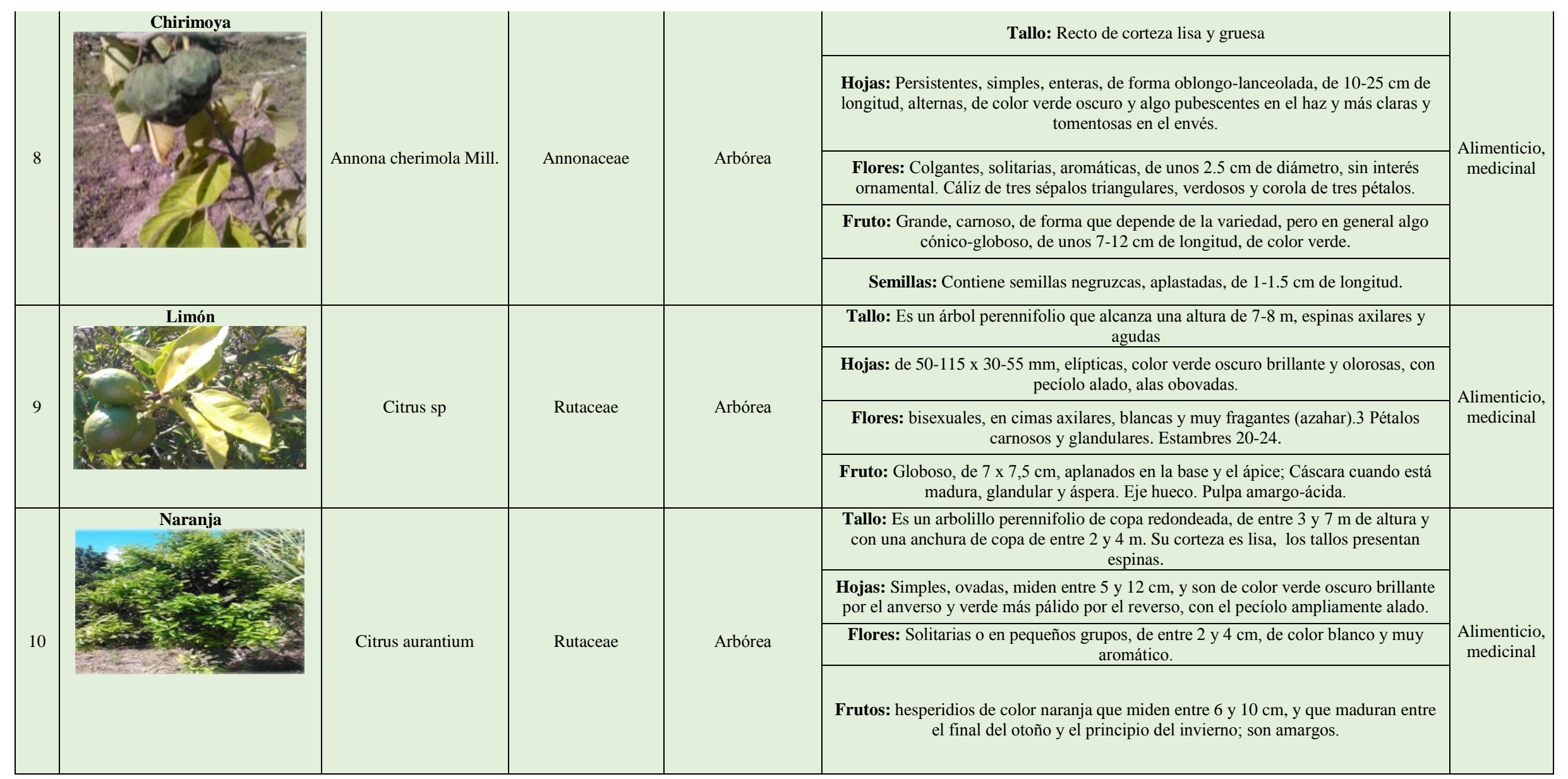




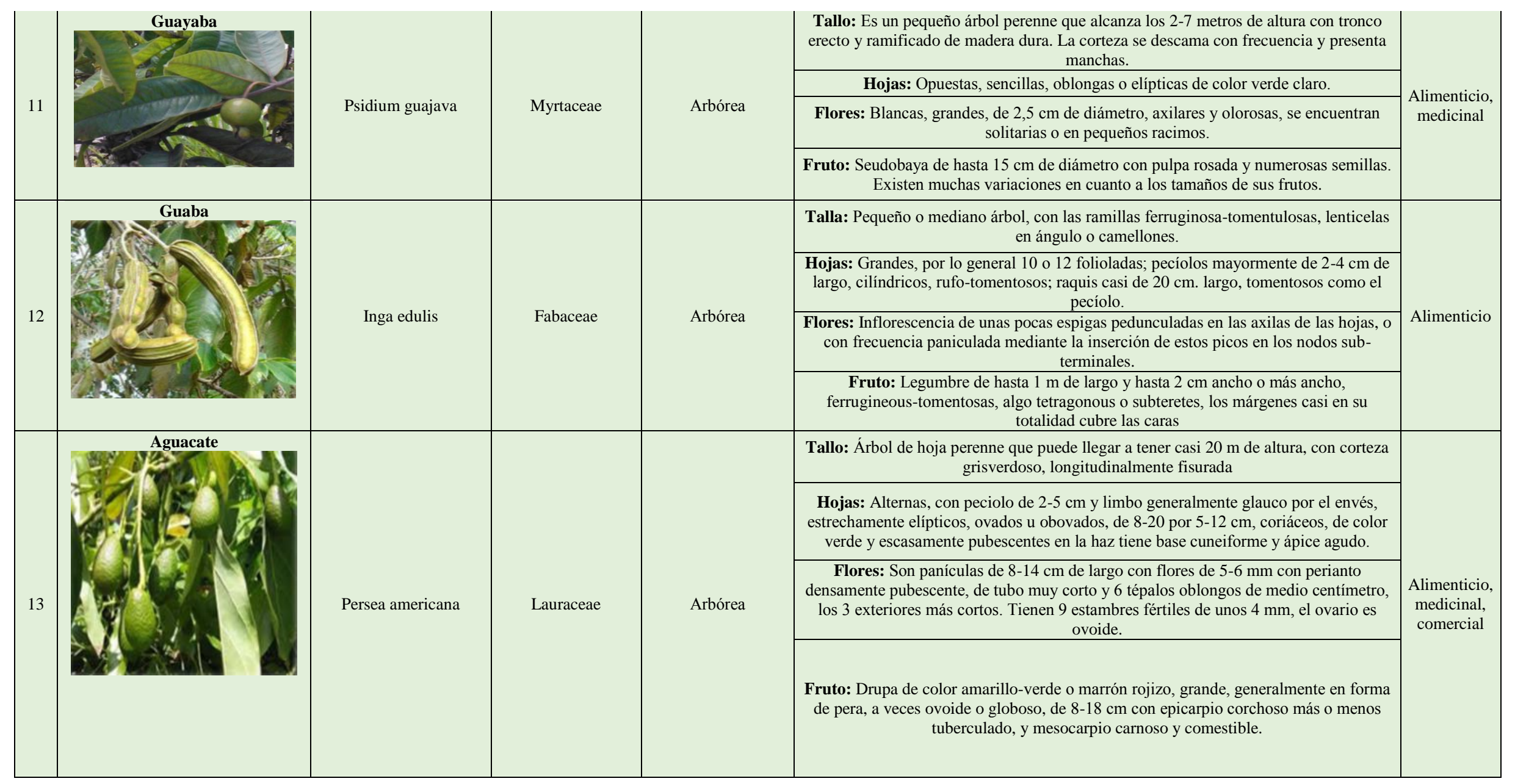




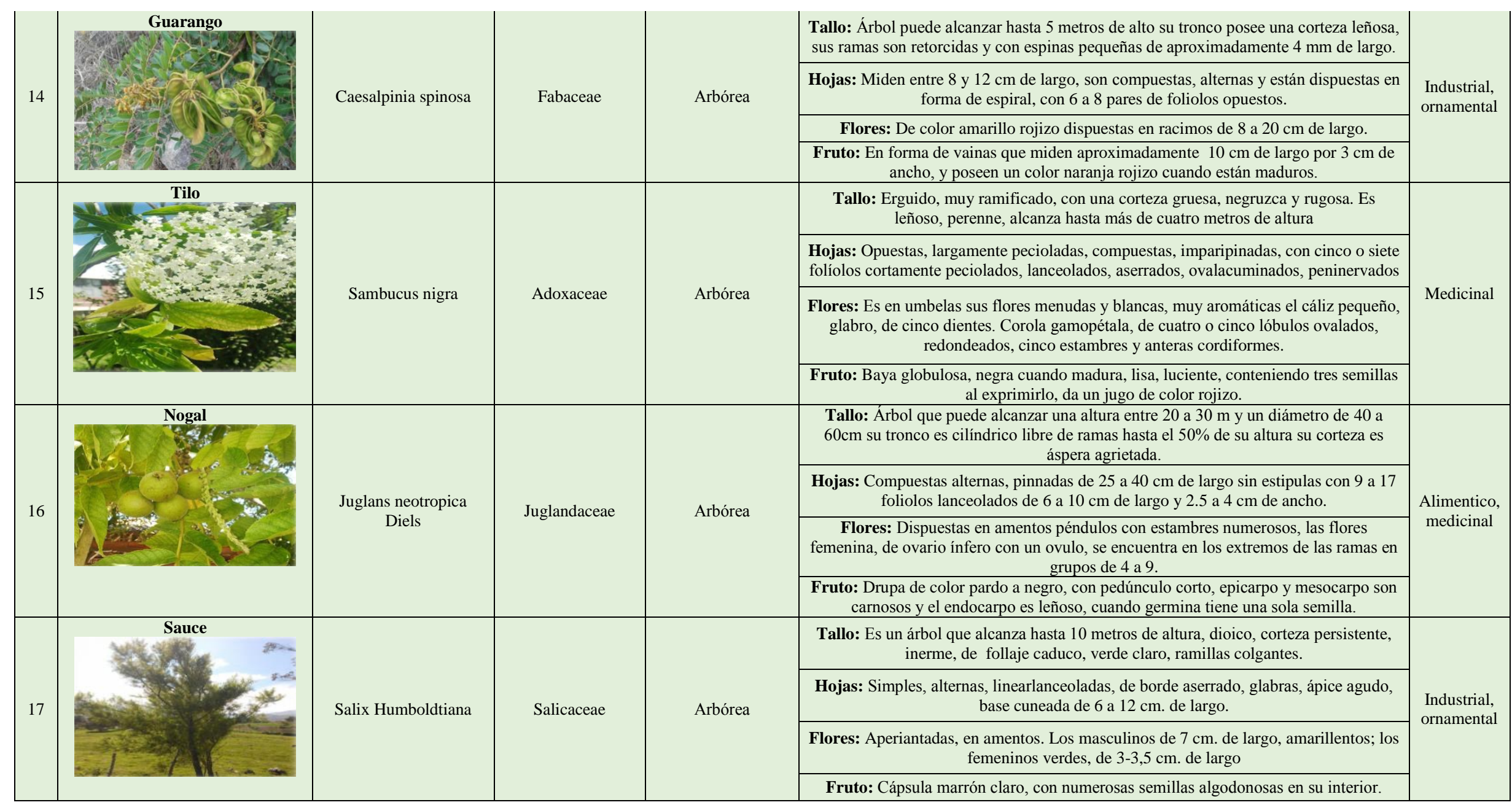




\begin{tabular}{|c|c|c|c|c|c|c|}
\hline \multirow{6}{*}{18} & \multirow{6}{*}{ Eucalipto } & \multirow{6}{*}{ Eucalyptus globulus } & \multirow{6}{*}{ Myrtaceae } & \multirow{6}{*}{ Arbórea } & $\begin{array}{l}\text { Sistema radical: Produce raíces en todo el suelo perfil, enraizamiento varios pies de } \\
\text { profundidad en algunos suelos. }\end{array}$ & \multirow{6}{*}{ Industrial } \\
\hline & & & & & Tallo: Son árboles pueden medir de $45-75 \mathrm{~m}$ de altura y 2 metros de diámetro. & \\
\hline & & & & & Hojas: Maduras son estrechas, en forma de hoz y verde brillante oscuro. & \\
\hline & & & & & $\begin{array}{l}\text { Flores: Los brotes son top en forma, acanalado y verrugosa y tienen un aplanado } \\
\text { opérculo (tapa en el capullo de la flor) que lleva un mando central. }\end{array}$ & \\
\hline & & & & & $\begin{array}{l}\text { Fruto: Los frutos son leñosas y van desde } 1,5 \text { hasta } 2,5 \mathrm{~cm}(0,59-0,98 \text { pulgadas }) \text { de } \\
\text { diámetro. }\end{array}$ & \\
\hline & & & & & $\begin{array}{l}\text { Semillas: Numerosas pequeñas semillas se desprenden a través de válvulas } \\
\text { (numeración de entre } 3 \text { y } 6 \text { por fruto) que se abren en la parte superior de la fruta. }\end{array}$ & \\
\hline \multirow{2}{*}{19} & \multirow[t]{2}{*}{ Pino } & \multirow{2}{*}{ Pinus radiata } & \multirow{2}{*}{ Pinaceae } & \multirow{2}{*}{ Arbórea } & $\begin{array}{l}\text { Tallo: Es un árbol de talla media a elevada, de aproximadamente } 30 \text { metros de altura, } \\
\text { crecimiento rápido ya que alcanza un diámetro de tronco de más de } 40 \text { pulgadas. Tiene } \\
\text { el tronco recto con ritidoma grueso de color pardo-rojizo. }\end{array}$ & \multirow{2}{*}{ Industrial } \\
\hline & & & & & $\begin{array}{c}\text { Hojas: De agujas de unos } 15 \mathrm{~cm} \text { de longitud agrupadas en tres. Estróbilos ovoides de } \\
7-14 \mathrm{~cm} \text { de longitud agrupados en verticilos de } 3-5 \text { con las escamas externa } \\
\text { prominentes. }\end{array}$ & \\
\hline \multirow{3}{*}{20} & & \multirow{3}{*}{ Cupressus sempervirens } & \multirow{3}{*}{ Cupressaceae } & \multirow{3}{*}{ Arbórea } & $\begin{array}{l}\text { Tallo: Pueden alcanzar los } 20 \mathrm{~m} \text { de altura con un diámetro aproximado de unos } 60 \mathrm{~cm} \text {. } \\
\text { Su porte es piramidal, de crecimiento rápido. Poseen un tronco recto y de corteza } \\
\text { delgada. }\end{array}$ & \multirow{3}{*}{ Industrial } \\
\hline & & & & & $\begin{array}{l}\text { Hojas: Muy pequeñas (2-6 mm de longitud) con forma de escama, alineadas en } \\
\text { parejas opuestas y decusadas. }\end{array}$ & \\
\hline & & & & & $\begin{array}{l}\text { Flores: Las flores masculinas forman conos ovales de color verdoso que cuelgan de } \\
\text { las puntas de las ramas. Los femeninos son ligeramente esféricos. }\end{array}$ & \\
\hline \multirow{3}{*}{21} & \multirow[t]{3}{*}{ Papaya } & \multirow{3}{*}{ Carica papaya } & \multirow{3}{*}{ Fabaceae } & \multirow{3}{*}{ Arbustiva } & $\begin{array}{l}\text { Tallo: Tronco sin ramas, de una altura entre } 1,8 \text { y } 2,5 \mathrm{~m} \text {, presenta un tallo ramificado, } \\
\text { de } 2-10 \mathrm{~m} \text { de altura, con el tronco recto, cilíndrico, suave, esponjoso-fibroso, jugoso, } \\
\text { hueco. }\end{array}$ & \multirow{3}{*}{$\begin{array}{c}\text { Alimenticio } \\
\text { medicinal }\end{array}$} \\
\hline & & & & & $\begin{array}{l}\text { Hojas: Alternas, aglomeradas en el ápice del tronco y ramas, de pecíolo largo de } 25- \\
75 \mathrm{~cm} \text { el haz de la hoja es de color verde oscuro o verde amarillo, brillante, el pecíolo } \\
\text { es redondeado de color verde amarillento, teñido con morado claro o violeta. }\end{array}$ & \\
\hline & & & & & Flores: Femeninas o flores hermafroditas y otros con flores masculinas. & \\
\hline
\end{tabular}




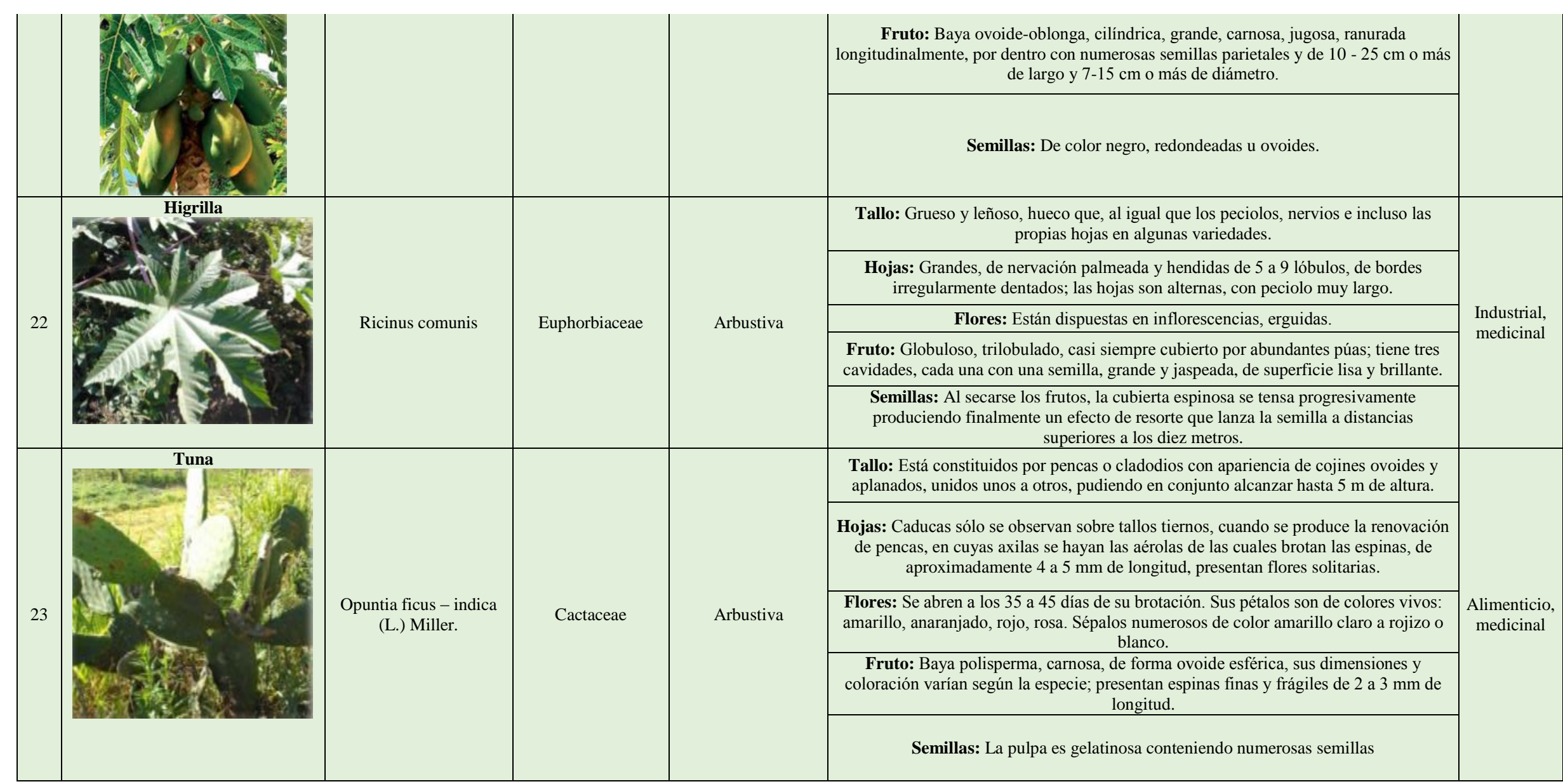




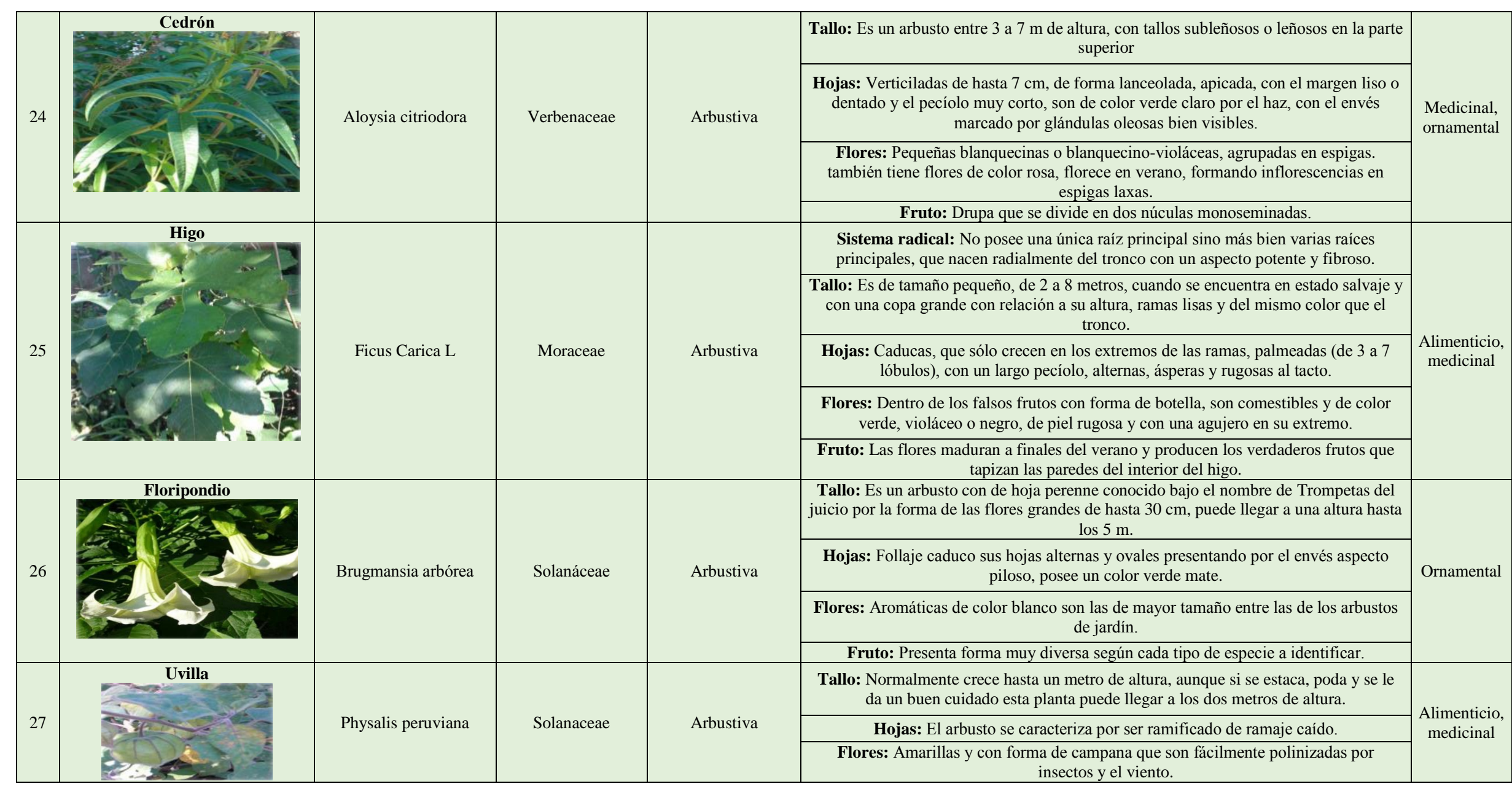




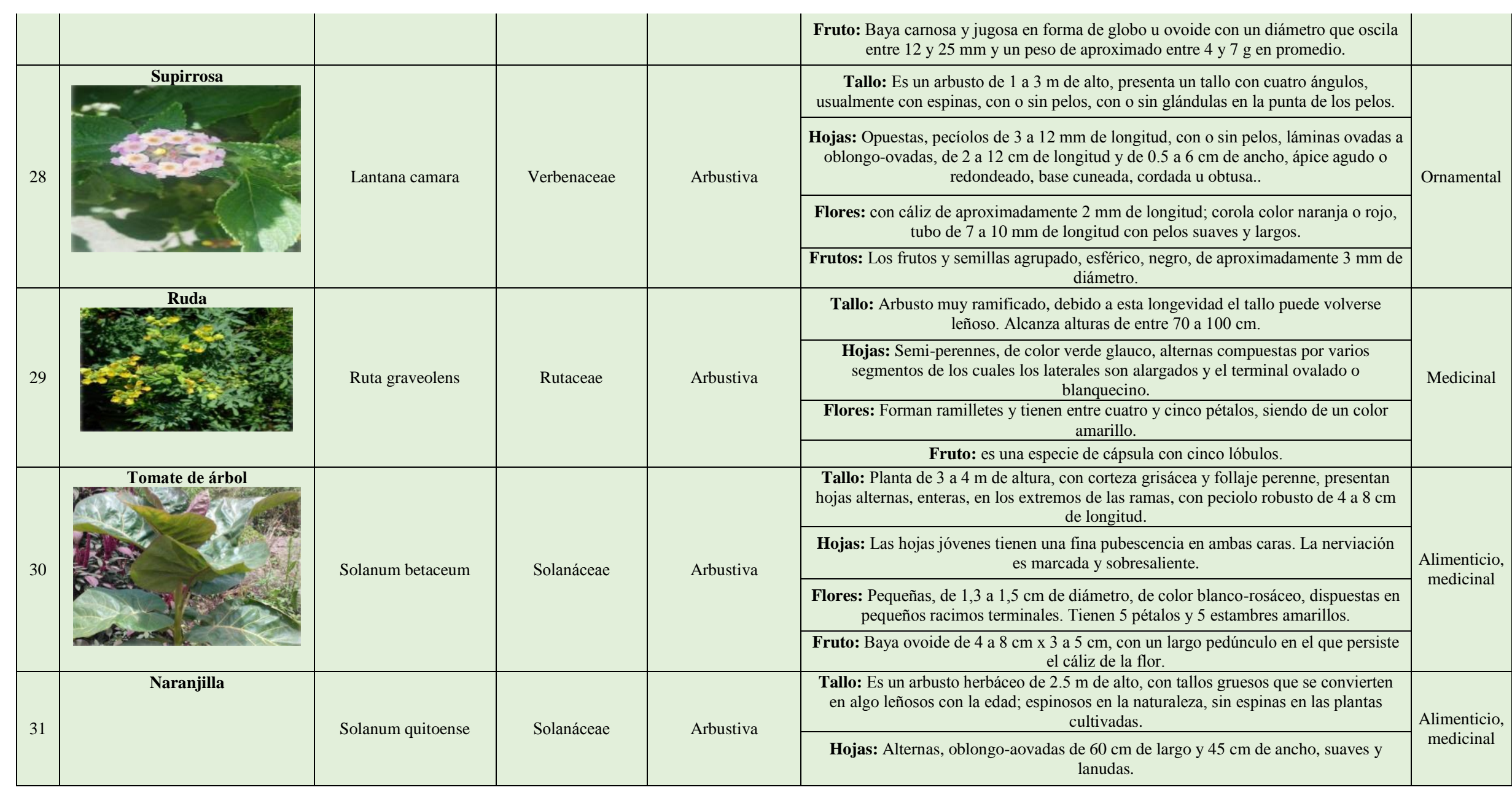




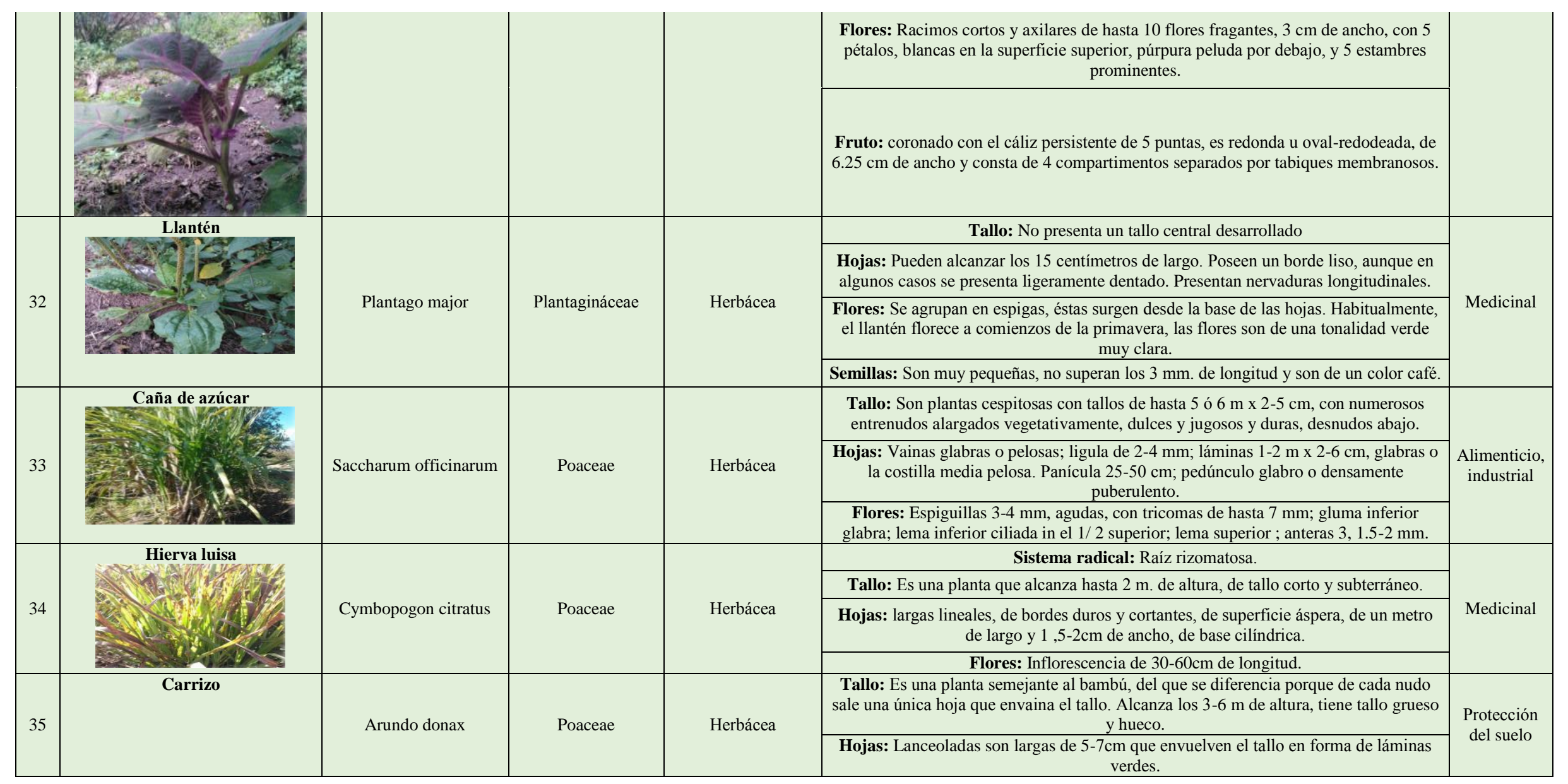




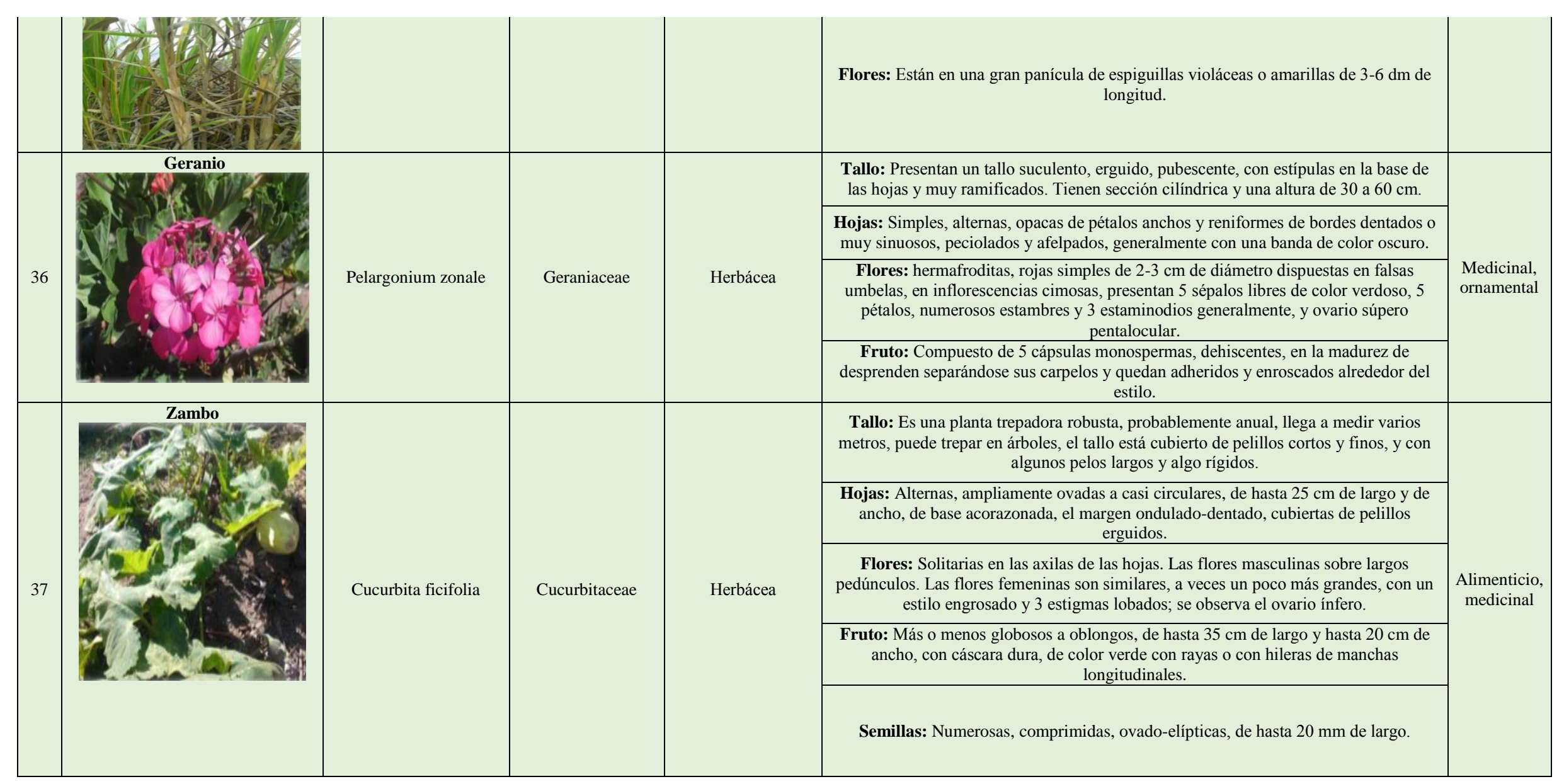




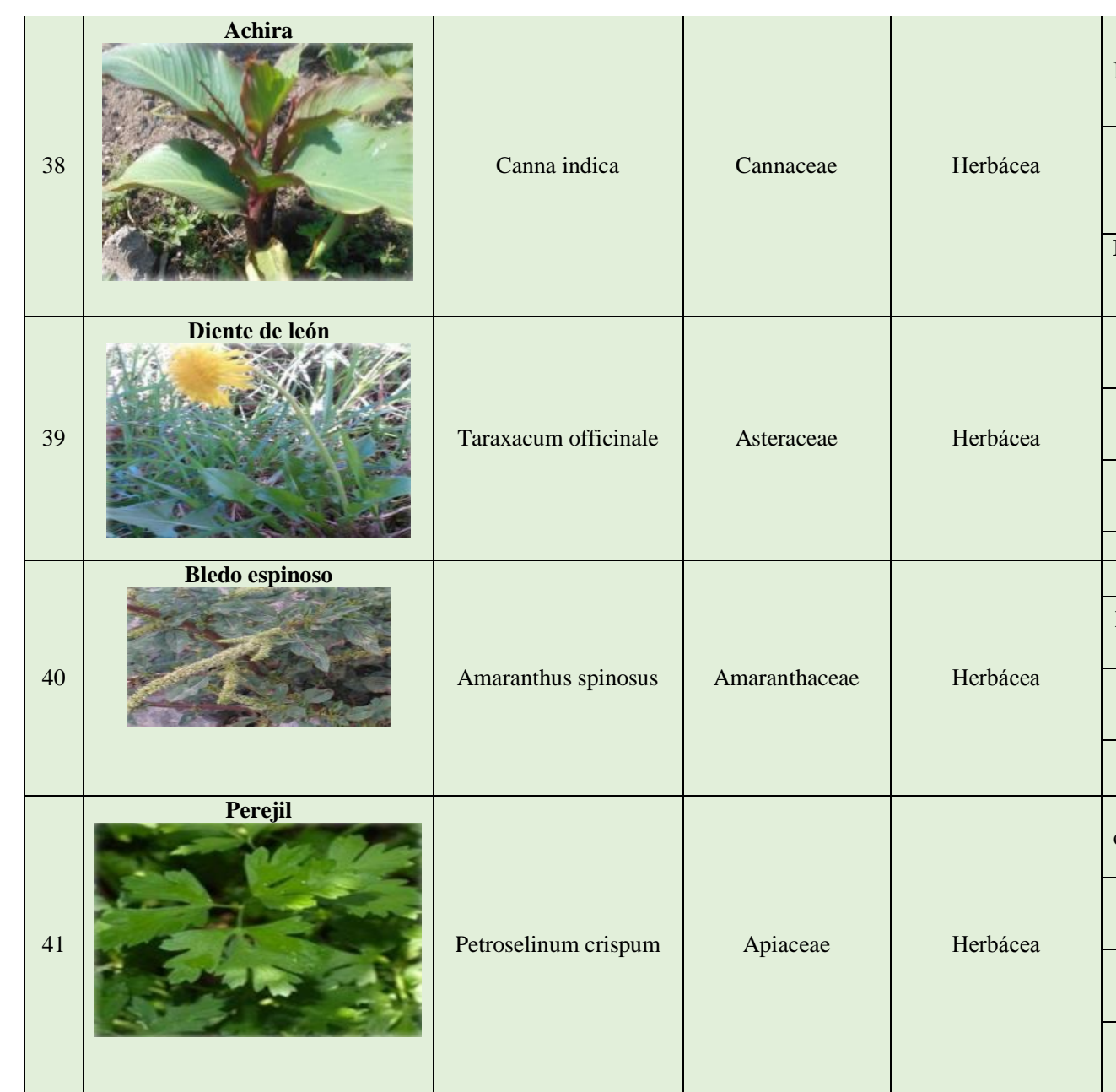

Tallo: Planta herbácea perenne, de rizoma carnoso y ramificado de hasta 20 x $15 \mathrm{~cm}$. La superficie del rizoma está labrada por surcos transversales, de la parte inferior salen raicillas blancas y del ápice.

Hojas: Anchas, de color verde o verde violáceo, con pecíolos cortos y láminas elípticas, que pueden medir de 30 a $60 \mathrm{~cm}$ de largo y 10 a $25 \mathrm{~cm}$ de ancho, con la base obtusa o estrechamente cuneada y el ápice es cortamente acuminado o agudo.

Flores: Inflorescencia en racimo terminal con 6-20 cincinos de 1-2 flores. Flores sobre pedicelos de 0,2-1 cm de largo, de color rojo o amarillo-anaranjado, excepto en algunos cultivares, de 4,5-7,5 cm de largo, con los sépalos estrechamente triangulares.

Tallo: Es una planta perenne con raíz primaria larga y roseta basal, suele alcanzar 40 $\mathrm{cm}$ de altura. El tallo permanece siempre en un estado extremadamente acortado.

Hojas: Alternas lanceoladas con una nervadura central, sin peciolo diferenciado, pinnatipartidas con lóbulos en forma triangular de márgenes dentados y agudos.

Medicinal

Flores: hermafroditas de un color amarillo dorado que la hacen fácilmente identificable. Corola en lígulas terminada en cinco pequeños dientes.

$$
\text { Fruto: Aquenio con largo pico y vilano. }
$$

Tallo: es rojizo, ramificado, erecto y espinoso, de 0,5 a $2 \mathrm{~m}$ de altura.

Hojas: Alternas ovaladas de 8 a $32 \mathrm{~cm}$ de largo con pecíolo de $14 \mathrm{~cm}$ de longitud, con espinas en la base (axila).

Flores: Inflorescencia, axilar en ovillo y en la terminación de las ramas densa en panículas con flores pequeñas amarillas, verdosas o crema.

Semillas: Produce miles de semillas brillantes de color café oscuro, mediante las cuales se propaga fácilmente.

Tallo: Planta herbácea perenne en la que sus tallos foliares no pasan los 15 centímetros de altura, y sus tallos con flores hacen más de medio metro, llegando hasta

$$
\text { el metro de altura. }
$$

Hojas: Lisas. Las hojas presentan morfologías diferentes dependiendo de su

localización en la planta. Las inferiores son tripinnadas y muchas veces rizadas.

Alimenticio,

medicinal, industrial (1) .

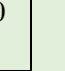
on

asta

ta
Flores: Crecen en umbela de hasta 5 centímetros de diámetro. Las flores son pequeñas, de tan solo unos milímetros, y amarillas.
Fruto: Con unos frutos de 4 milímetros que contiene unas 600- 700 semillas diminutas. Por eso se emplea normalmente el fruto como simiente. edicinal 


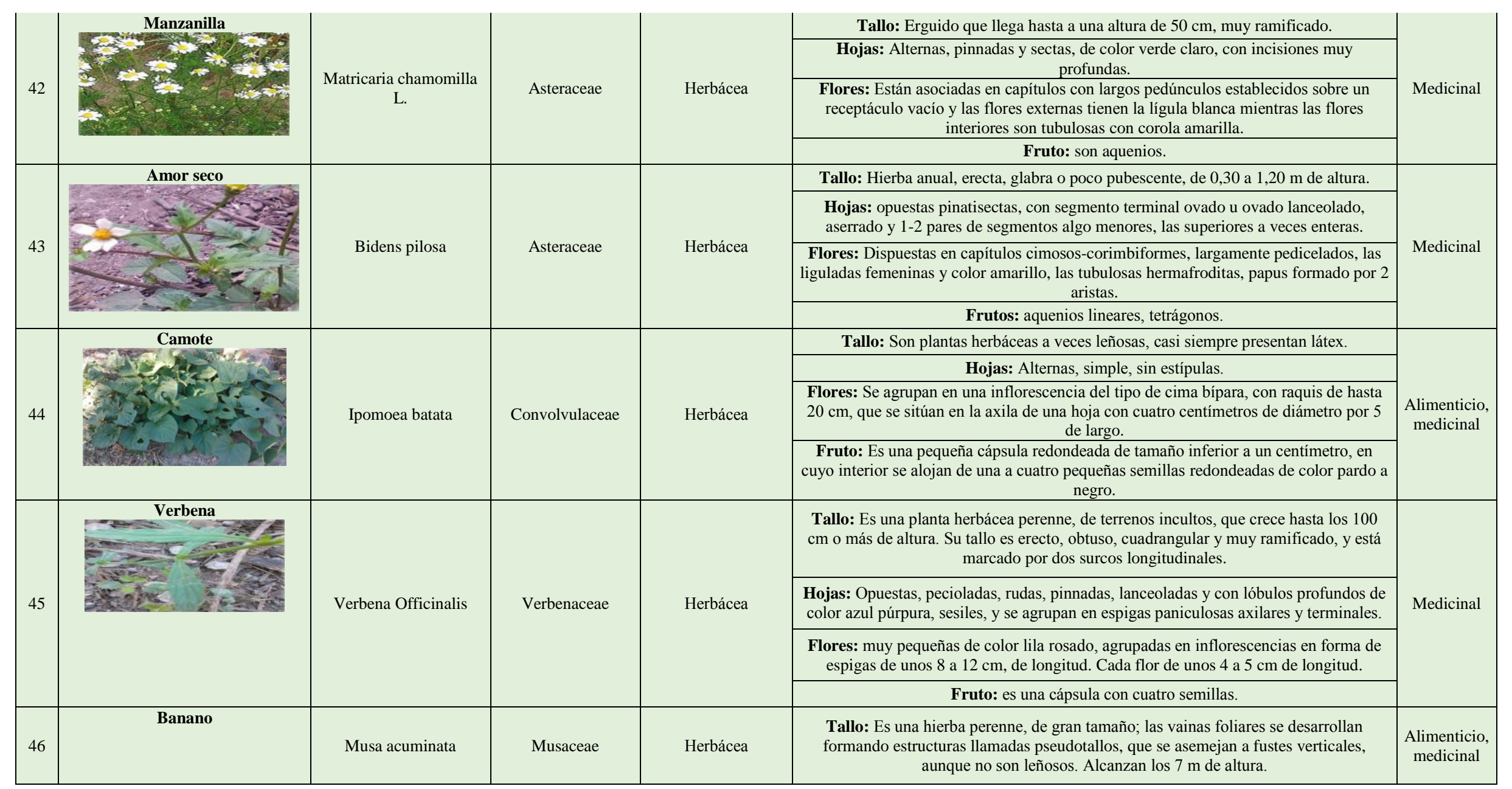




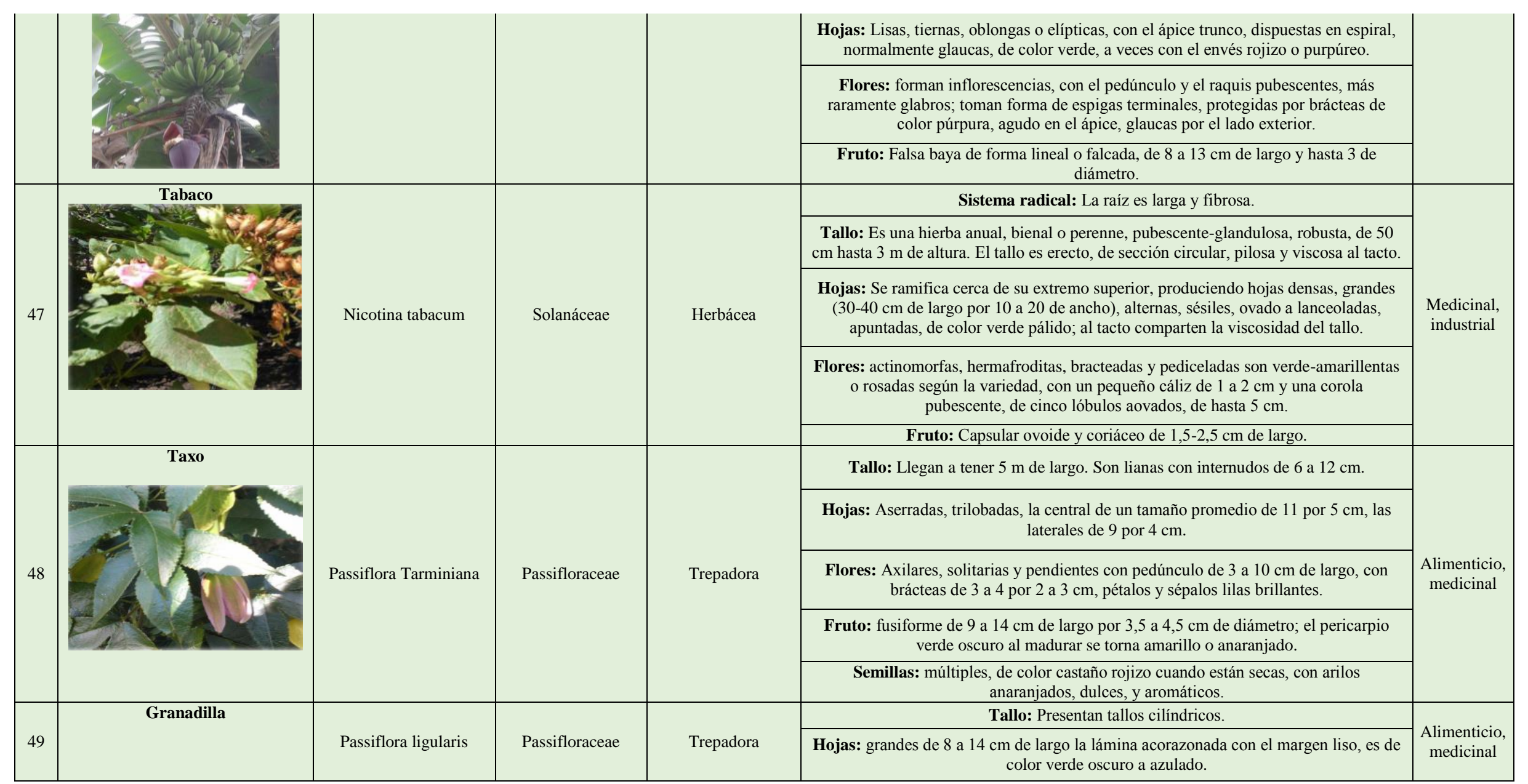



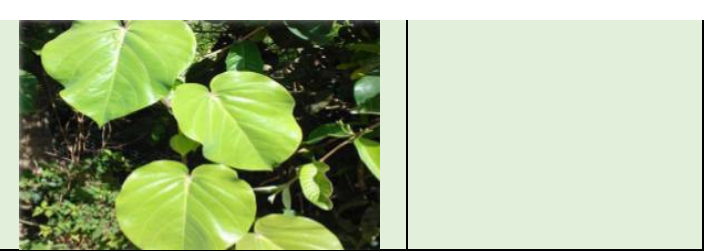

Flores: Pueden medir de 6 a $8 \mathrm{~cm}$ de diámetro los sépalos y pétalos son de color blanco y amarillento y la corono con bandas alternas moradas y blanca.

\section{Elaboración: Propia}

Registro actualizado de nuevas especies vegetales

Cuadro 2. Matriz resumen actualizada de la flora de la comunidad Piñancay

\begin{tabular}{|c|c|c|c|c|c|c|}
\hline \multirow[b]{2}{*}{$\mathbf{N}^{\mathbf{o}}$} & \multirow[b]{2}{*}{ Nombre vulgar } & \multicolumn{3}{|c|}{ Taxonomía } & \multirow[b]{2}{*}{ Morfología } & \multirow[b]{2}{*}{ Usos } \\
\hline & & Nombre científico & Familia & $\begin{array}{c}\text { Tipo de } \\
\text { vegetación }\end{array}$ & & \\
\hline \multirow[b]{2}{*}{1} & & \multirow[b]{2}{*}{ Amaranthus quitensis } & \multirow[b]{2}{*}{ Amaranthaceae } & \multirow[b]{2}{*}{ Herbácea } & $\begin{array}{c}\text { Tiene cotiledones ovales lanceolados con lámina de 13- } \\
15 \mathrm{~mm} \text { x 2-3 mm; nervadura central poco visible; } \\
\text { pecíolo mediano. }\end{array}$ & \multirow[b]{2}{*}{ Alimenticio } \\
\hline & & & & & $\begin{array}{c}\text { Hojas: Subopuestas, ovadas lanceoladas, ápice } \\
\text { emarginado, borde entero; nervadura central bien } \\
\text { visible; pecíolo de } 1 / 5 \text { del largo de la lámina. Hipocótilo } \\
\text { largo }\end{array}$ & \\
\hline \multirow[b]{3}{*}{2} & \multirow[t]{3}{*}{ Falso chamico } & \multirow[b]{3}{*}{ Nicandra physalodes } & \multirow[b]{3}{*}{ Solanaceae } & \multirow[b]{3}{*}{ Herbácea } & $\begin{array}{c}\text { Tallo: Es una herbácea anual de hasta } 1 \mathrm{~m} \text { de altura y } \\
\text { vigorosa ramificación. }\end{array}$ & \multirow[b]{3}{*}{ Medicinal } \\
\hline & & & & & $\begin{array}{c}\text { Hojas: son ovadas, de color verde medio, con márgenes } \\
\text { dentados a ondulados. }\end{array}$ & \\
\hline & & & & & $\begin{array}{l}\text { Flores: de color violeta claro, con la garganta blanca, } \\
\text { miden } 5 \mathrm{~cm} \text { o más de diámetro con forma acampanada } \\
\text { hasta el final de la floración, cuando van adquiriendo } \\
\text { forma de farolillo. Florece en verano hasta principios } \\
\text { del otoño. }\end{array}$ & \\
\hline \multirow[b]{2}{*}{3} & \multirow[t]{2}{*}{ Rábano silvestre } & \multirow[b]{2}{*}{ Raphanus raphanistrum } & \multirow[b]{2}{*}{ Brassicaceae } & \multirow[b]{2}{*}{ Herbácea } & $\begin{array}{c}\text { Sistema radical: Su raíz está engrosada porque allí } \\
\text { almacena almidón de reserva. }\end{array}$ & \multirow[b]{2}{*}{ Alimenticio } \\
\hline & & & & & $\begin{array}{l}\text { Tallo: Sus primeras hojas crecen en forma de roseta en } \\
\text { la base de un tallo erecto pubescente, mientras que las } \\
\text { demás crecen a lo largo de él. }\end{array}$ & \\
\hline
\end{tabular}




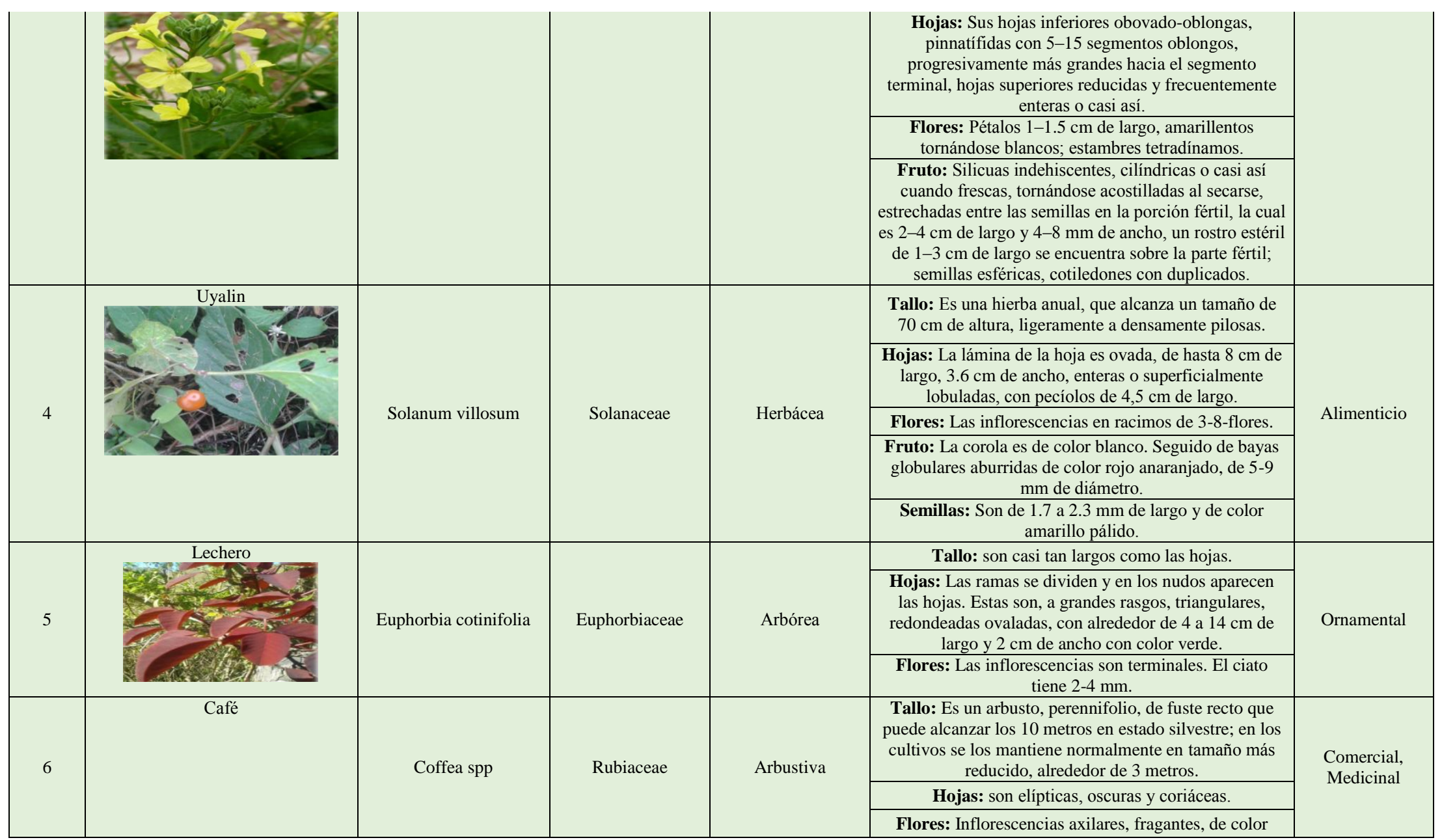




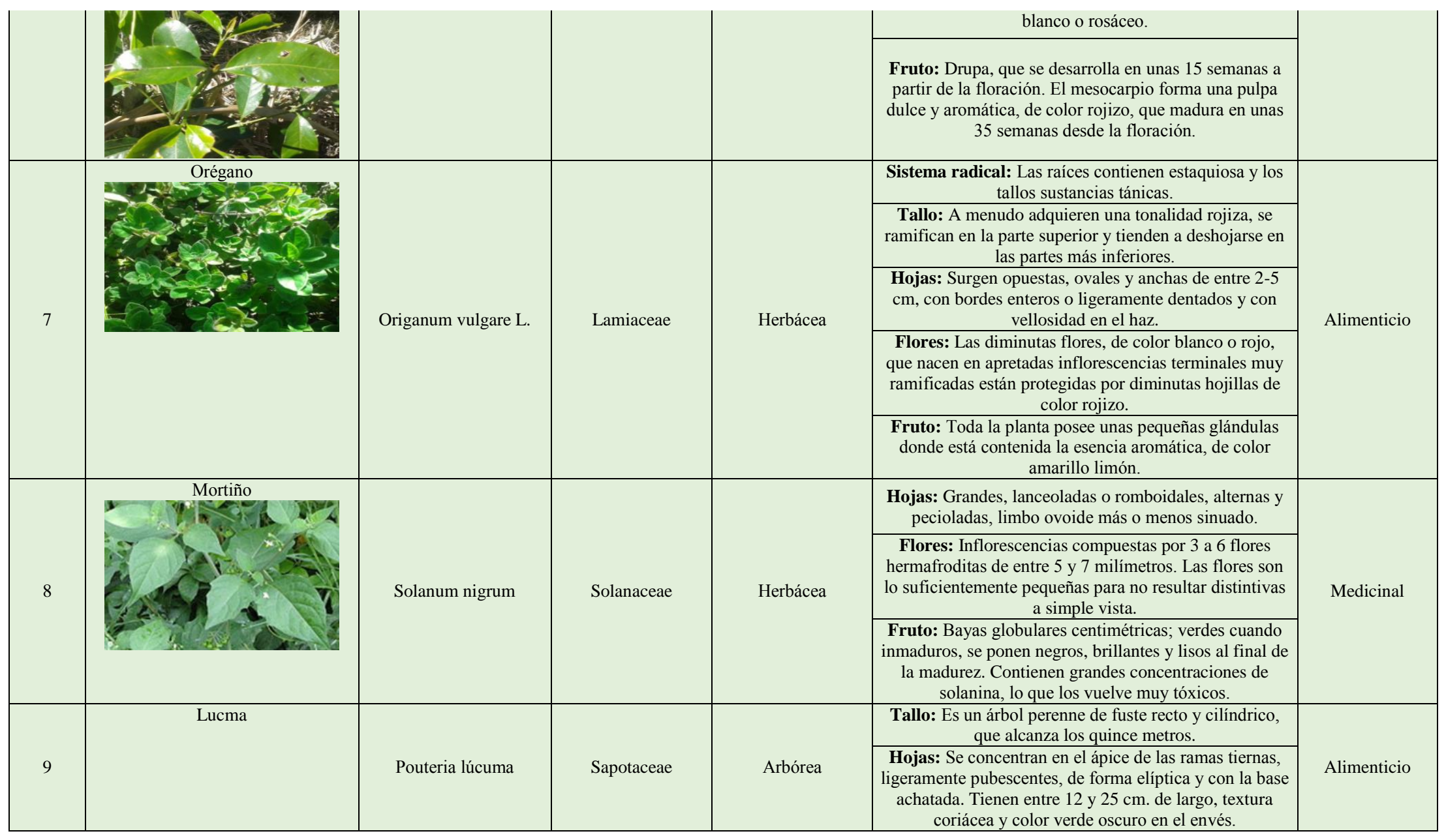




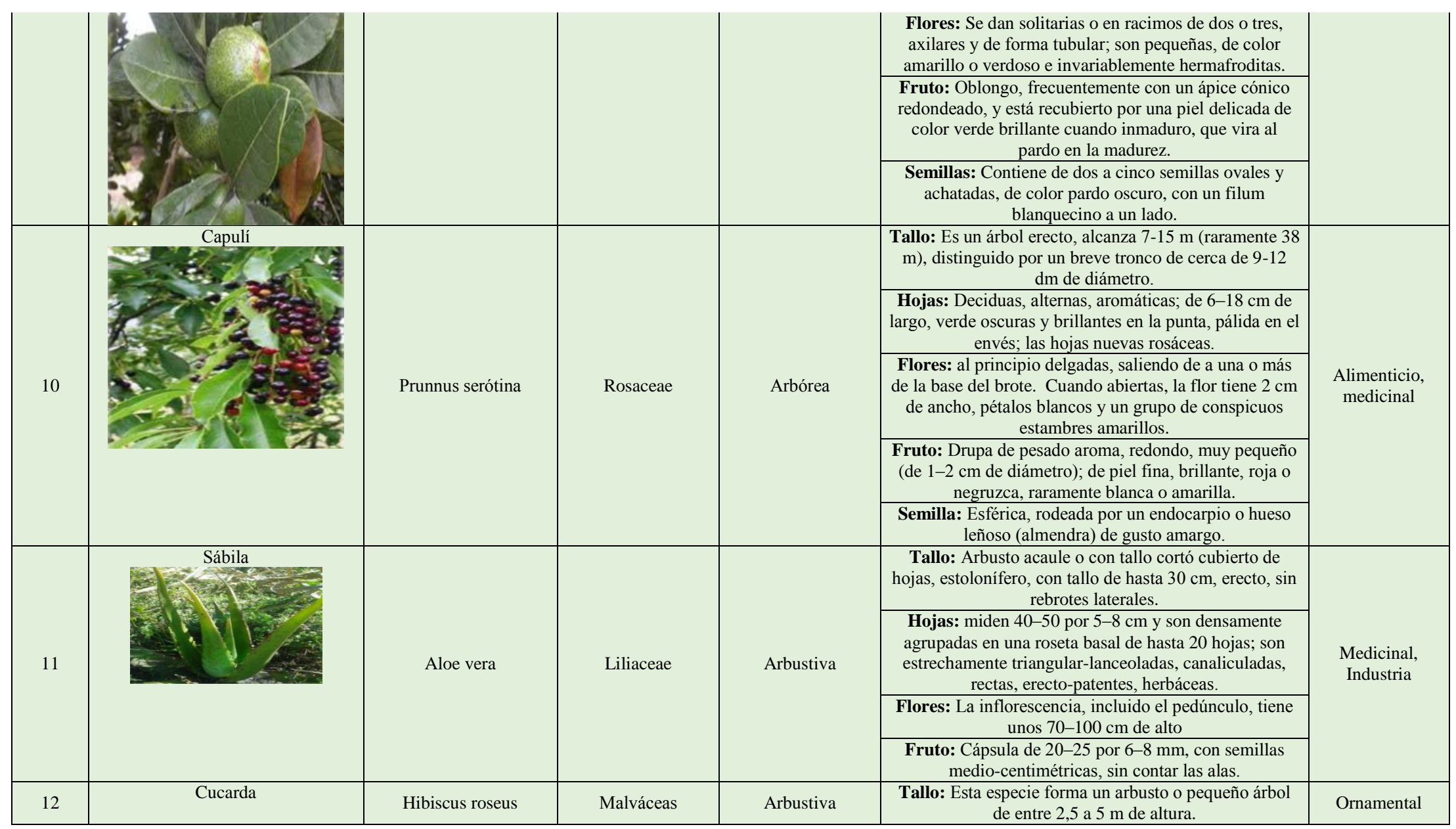




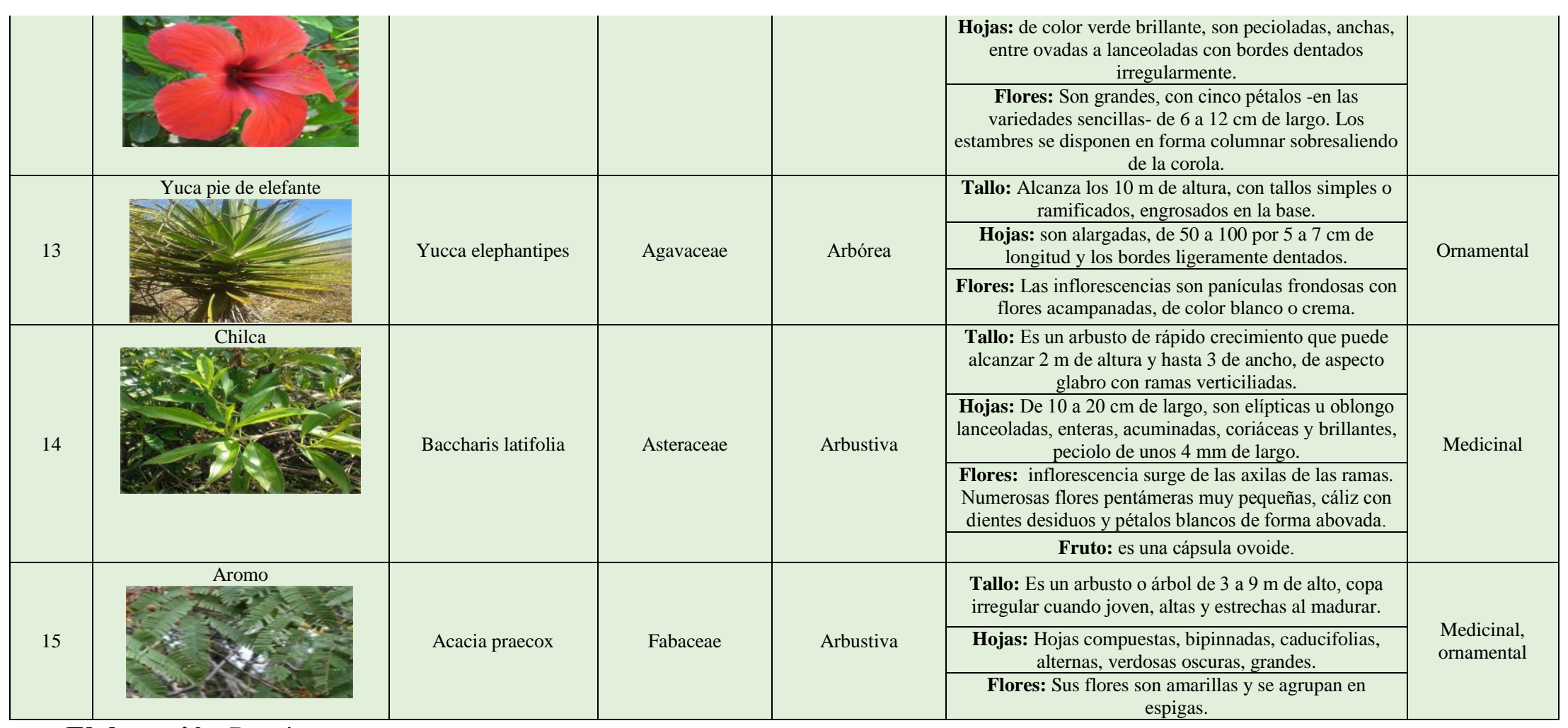

Elaboración:Propia 
Cuadro 3. Validación del inventario de flora

\begin{tabular}{|c|c|}
\hline \multicolumn{2}{|c|}{ VALIDACIÓN DEL INVENTARIO DE FLORA } \\
\hline Inventario validado & 49 \\
\hline Inventario actualizado & 15 \\
\hline TOTAL & 64 \\
\hline
\end{tabular}

Elaboración: Propia

Grafico 1. Validación del inventario de flora

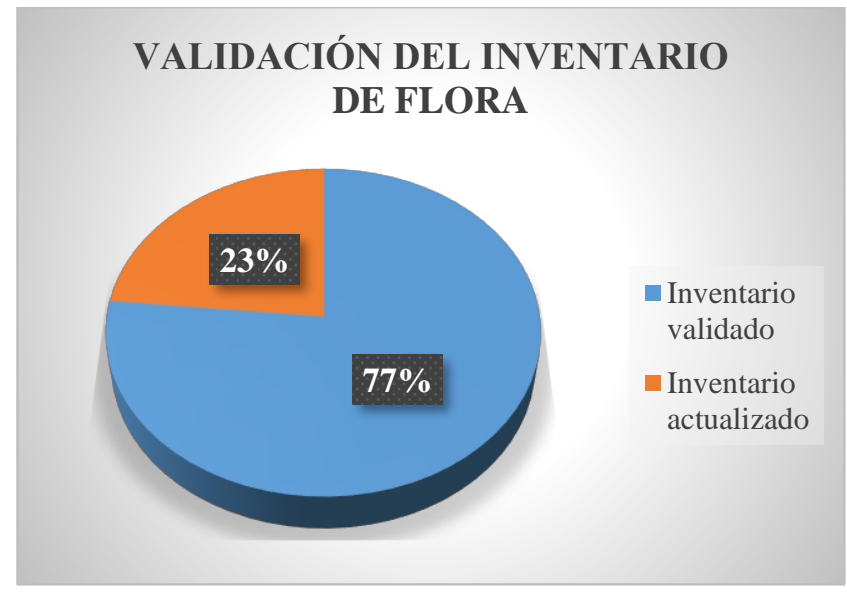

\section{Conclusiones}

- $\quad$ Del 100\% de la flora inventariada en la comunidad Piñancay, el 77\% fue validado lo cual corresponde a 49 especies y un $23 \%$ forma parte del inventario actualizado que consta de 15 especies.

- $\quad$ Se realizó la identificación morfológica y taxonómica tanto de las 49 especies del inventario validado como de las 15 especies del inventario actualizado de la comunidad Piñancay.

- Se ha determinado el tipo de vegetación existente en el inventario validado de la comunidad Piñancay, teniendo un 43\% de vegetación herbácea, $27 \%$ arbórea, $27 \%$ arbustiva y un $4 \%$ vegetación trepadora. En cuanto, al tipo de vegetación existente en el inventario actualizado un $40 \%$ corresponde a vegetación herbácea, 33\% arbustiva y un $27 \%$ vegetación arbórea. 


\section{References:}

1. Alvarado, J. (2006). "Sector Agrícola en el combate de la pobreza rural". http://www.redalyc.org/articulo.oa?id=72920534012.

2. Castro, G., Lozano, A., Fernánde, G. \& Rodríguez, D. (2005). "Agrobiodiversidad y Pobreza" http://www.redalyc.org/articulo.oa?id=49520714.

3. Deutsche Gesellschaft für - Technische Zusammenarbeit GTZ. (2000). "Gestión de Agrobiodiversidad en Áreas Rurales. Proyecto sectorial de gestión a la actividad agropecuaria."

4. Gargoloff, N.A. (2009). "Análisis del conocimiento y manejo de la agrobiodiversidad en horticultores capitalizados, familiares $y$ orgánicos de La Plata, Argentina".

5. International Fund for Agricultural Development - IFAD (2001). "Informe Sobre la pobreza Rural 2001: El desafío consistente en acabar con la pobreza rural". Fondo Internacional de Desarrollo Agrícola. Primera edición en inglés publicada por Oxford University Press (Reino Unido) en 2001. https:/www.ifad.org/documents/10180/6ec205c1-b70c-4e1f-b9da0a6a2ce4c79a.

6. Phelean, M. (2006). "La pobreza en Venezuela" Fundación Escuela de Gerencia Social. Ministerio del Poder Popular para la Planificación y Desarrollo.

7. Rivera, C. (2015). "Estudio arquebotánico de los saberes ancestrales de la agrobiodiversidad de la comunidad Piñancay, parroquia Capsol, cantón Chunchi."

8. Rojas, J., Espinoza, R. \& Torres, L. (2016). "Estudio de la Agrobiodiversidad de Raqaypampa" https://www.researchgate.net/publication/317843167_ESTUDIO_DE _LA_AGROBIODIVERSIDAD_DE_RAQAYPAMPA?ev=srch_pub

9. Spicker Paul (2009). "Definiciones de pobreza: doce grupos de significados".

http://biblioteca.clacso.edu.ar/ar/libros/clacso/crop/glosario/06spicker .pdf.

10. Thompson, R. (2003). "Global Food Security and Rural Poverty" in Nestle: Creating Shared Value and Rural Development Report 2010. 